\title{
The Mediating Effect of Job Satisfaction on Employee Loyalty: A Case Study of a Developer Company in Malaysia
}

\section{Zainuddin Zakaria, Mutiiah Mohamad, Md Noh Abd Majid, Nurul Ulfa Abdul Aziz, and Kartini Mat Rashid}

Faculty of Business and Management, Universiti Teknologi MARA Terengganu,Dungun, Malaysia

\section{Abstract}

Employees' loyalty is being described as the ability of the employee or staff members of the organization to stay and contribute well in their jobs for such a long term. In the recent years, resignation of employees did show an increment in many companies in Malaysia. This research specifically study on a developer company which is one of the constructions developers company in Johor, Malaysia The purpose of this study

Corresponding Author:

Zainuddin Zakaria

hzainuddin67@gmail.com

Received: 10 February 2019

Accepted: 14 March 2019

Published: 28 March 2019

Publishing services provided by Knowledge E

(c) Zainuddin Zakaria et al. This article is distributed under the terms of the Creative Commons Attribution License, which permits unrestricted use and redistribution provided that the original author and source are credited.

Selection and Peer-review under the responsibility of the ICIEBP Conference Committee. is to investigate the factors of training, rewards and benefits and working condition as determinants toward employee loyalty and how job satisfaction mediate the relationship between independent variables and dependent variables as the factors that influence the employee loyalty in organizations. A stratified sampling method was adopted as the sampling method and questionnaires is chosen as the research instrument adopted previous researcher and adopt it into this research. Respondents of this research consists of 155 respondents who are employees of the developer company. In general, we conclude that employee loyalty in the developer company has positive relation between the working condition, rewards and benefits, training and job satisfaction and confirms the partial mediation of Job Satisfaction between the independent variables, rewards/benefits and training with employee loyalty.

Keywords: Employee Satisfaction, Employee Loyalty, Working Condition, Training, Malaysia

\section{Introduction}

Employee loyalty has being described as the ability of the employee or staff members of the organization to stay and contribute well in their jobs for such a long term. Silvestro (2002), in the previous research said that a way in order to measure the employee loyalty could be by looking at their serving period in the company which it should be more than five years to be considered as a loyal employee in the organizations. In contrast, Phaneuf (2013) argues that the indicator taken to measure the employee loyalty is 
measured by the time the employee working for the company as a whole and needs to include their term of commitment level derived by them during their performance on the job. In this research the researchers focuses on the study on the factors that influence the employee loyalty in the organization is due to the economic changing, downsizing of market, cooperate restructuring which, in return making the definition of employee loyalty be changeable depending on the varied situations. Hence, obviously loyal employees must have a high commitment towards their job and it is proven by their action, making seniority in a company unnecessary considered as a loyal employee.

The research conducted by Khuong and Tien (2013) has shown, employee who resigned after working 1 to 2 years is represented about 39\% of employees and the rest did resign after 3 years of working. The company will face the increase of management cost to ensure that the employee can cope with their responsibilities and task. Moreover, young employees who has good academic qualifications are reported to have the highest intentions to change job after being employed for a certain period of time. The research by Khuong and Tien (2013) proved that employees in this group has the highest tendencies to switch job willingly if they receive offers that are more enticing from other companies. Hence, it is essential for organizations to find a way in enhancing their employee loyalty. In this study we are interested to identify what are the important factors that do significantly affect the employees' job satisfaction and their loyalty towards the organizations. Furthermore, this research is also intended to explain the direct and indirect effects of the job satisfaction on employee loyalty in detail. In brief, the suggestions for the organizations will be provided because it does function as practical guidelines to enhance employees' satisfaction and their loyalty.

\section{Problem Statement}

In a business context, the issues on improving job satisfaction and loyalty tend to be discussed most of the time. This is because these elements has become a strategic drive in a successful business. In most companies, they prefer to derive benefits by their own way, from their ethical efforts in the form of increased employee's satisfaction and loyalty; however, they yet have figured it out how to do it successfully. However, the Employment Policy Foundation Tabulation and Analysis Bureau of Labor Statistic (2011) statistic shows that employee's resignation from one company only after a few months of work to seek for another job did show an increase in number throughout recent years. 
In the asset development industries, (29\%) which is the third highest of turnover rates is represented by the construction industry. Moreover, the construction industry voluntary quit $(25 \%)$ are the third higher among the industries that monopolized by retail trade and leisure $\&$ hospitality industry. These will contribute a serious impact on the construction industry because the high turnover rates would incurred a cost to the organization in order to reduce the profit earn of the organization. Based on the survey data, it shows that the turnover replacement cost of the services industry may equal 15,000 dollars per employee.

\section{Literature Review}

Employee loyalty is closely related to employees' job satisfaction. However how the job satisfaction is being defined, it must be subjective and differently by the employees themselves personally as the job satisfaction is differ according to the workforce level or each of them. The loyalty of employee will be higher when the employees have high job satisfaction and willing to remain committed to work with the organization. Job satisfaction mainly focuses on the attitude of employee toward his current job while the employee loyalty contextual of understanding is expected to be wider in frameworks scope which is employee's attitude toward the organization (Chen, 2006). Previous research by Chang et al., (2010), employee job satisfaction is functioning as an antecedent to the employee loyalty. Hence, fulfilling the need of an employee in order to gain the employee satisfaction is a wise decision taken by the organization or company to have good and loyal employee. The degree of loyalty of employee can be improved when the satisfaction on working condition, rewards benefits, and the quality of training increased.

\subsection{Training}

In the new era of globalisation, the objective of the organization is to improve the business process through enhancing the way of learning to broaden the knowledge in the field of industry that stimulates the employees and organization towards better performance. According Jodlbauer et al., (2012), the number of empirical studies that have examined the effect of job satisfaction on the success of having training is still limited particularly in the context of construction organizations. Basically, the main focus of any organisation is to create a well engaged and committed employee resulting in better performance of the individuals and business (Burgard, 2014). 
In order to upgrade the level of performance, providing a training could help the process of improving the skills and knowledge of people which then mold their way of thinking. Thus, it is paramount for both employees and the management to be given training as it could lead towards better improvement. Hence, in order to achieve individual development, employee training needs to provide the employees to broaden their knowledge and enlarge their capacities in order to achieve company objectives goals instead of having a well-organized works.

\subsection{Working condition}

There are several factors that influence employee job satisfaction which include convenient working environment for doing the job, comfortable workplace like providing a good ventilation, safety workspace, and the degree of noise. These factors are postulated to influence employee job satisfaction and the loyalty of employee to the company since employees prefer working condition that provides high physical comfort and a good management of risk that will derive by the effective decision making on taking action in order to facilitate their work (Sutherland, 2013). Employee's job satisfaction will increase when the working condition which include the safety, hygiene and optimum working ambiance is provided by the company.

A working condition can be described as the environment where employee performs the duties and daily activities of operations and it prepares them to adapt with the physical and non-physical engagement. Noise level, fresh air, and the incentives like child care, also become a part of work condition. Thus, the workplace condition may impose a positive or negative impact towards the satisfaction level of employee's upon the nature of their working ambiance (Benn, Teo, \& Martin, 2015). This is because employees do well in a calm and conducive working condition. Hence, working ambiance do propose a positive and strong effect on employee satisfaction.

\subsection{Rewards/benefits}

In general, ffulfilling employees' needs, recognizing their efforts and presenting them with monetary and non-monetary rewards tend to help the organization in creating a great workforce for the organization which can be an important determinant towards a successful term of partnership between the employee and the organization itself; eventually, achieving company goals and objectives. This had been the rules and one of the goals set up by the company. Recognition should be given according to employees' 
effort to boost their morale resulting in increased productivity and decreased attrition rate. It is a proven fact that the motivated and dedicated workforce can change the fate of a company and able to bring it to another level. Human factor is the biggest contributing factor in the success of any organization. A satisfied workforce who executes their plans will help contribute to an organization's success.

\subsection{Job satisfaction}

According to Locke (1976), employee job satisfaction is defined as a pleasurable or a positive emotional state which resulting from the performance appraisal of one's job or job experience by the management of organization. Even though there is still no agreement and a precise description in the definition of employee job satisfaction, still it can be understood as the ability of an employee to give an opinion about the general emotion, behaviors and their forms of thinking about their job scope and workplace condition in order to be drawn out as a data comparison to others. Thus, job satisfaction is not static is influenced by other factors whereas, it may change if the other factor is changing in progress onwards.

Individual judgment about their own past and future financial situation is also stressed as one of the important indicators toward employee loyalty (Burton et.al, 2006). Furthermore, the relative wage is also shown to be significant as far as job satisfaction is concerned (Clark et al, 2008). The work of Al-Aameri (2000) loyalty is a psychological state and it characterizes by the good relationship of an employee with the organization which has an implications on their decision to remain with the organization, meanwhile job satisfaction represents an effective response to specific features of the job and an attitude toward a job (Chen, 2006).

Research conducted by Al-Aameri (2000) and Fang (2001) also proposed that there is a strong relationship employees' loyalty and employee job satisfaction, same goes as mentioned by (Wu \& Norman, 2006). In contrast, low job satisfaction may influence employees to switch jobs, make a change in their current jobs and careers in order to seek for better job satisfaction. In which, employees who are satisfied with their jobs have greater organizational loyalty than unsatisfied employees (Kim et al., 2005). Hence, we hope prove that when employee job satisfaction increased, their loyalty their employers will increase. 


\subsection{Conceptual framework}

From the discussion of the literature journals, the three determinants researcher had selected are training, rewards or benefits and working conditions the researcher's research theoretical framework. These three determinants are very important in influencing the employee loyalty mediate with employee job satisfaction among the employee in construction industry. Therefore, at this part, these variables would be form out as the conceptual framework shown in Figure 1:

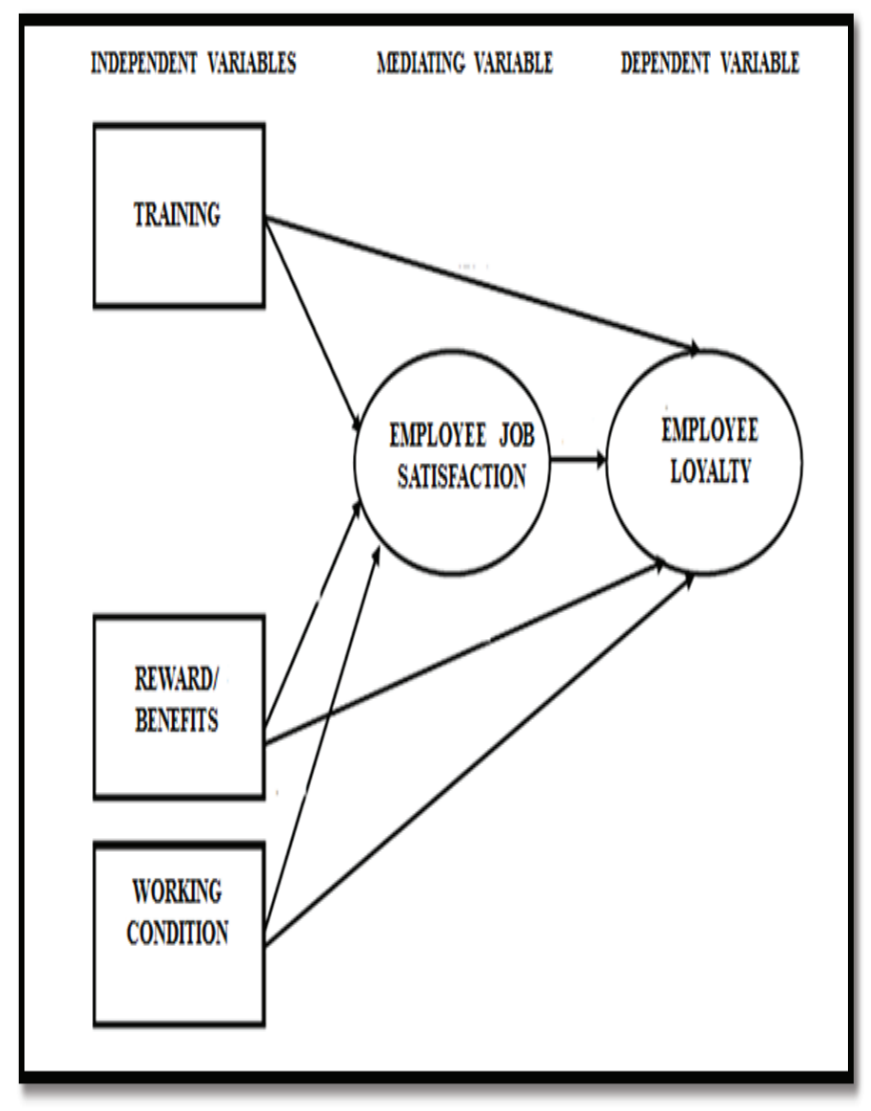

Figure 1: Conceptual Framework.

\section{Research Methodology}

To attain and meet the research objective, the researchers adopted a deductive and quantitative approaches where information are gathered from respondent through a survey using questionnaires To ensure validity and reliability on research findings are relevant, researcher used an appropriate questionnaire, sampling technique and data analysis method which also covers the accuracy and the quality of the research. 


\subsection{Population}

Employees of the developer company represented the population in this study. The research involved employees who are working in the developer Company. The questionnaire is distributed to employees from all departments using stratified random sampling. The total numbers of employees is 260 employees. The company is located in Johor, Malaysia. The data for this study was collected through self-administered questionnaires distributed by researcher.

\subsection{Research instrument}

Questionnaire is used as a research instrument in this research. Questionnaire is used rather than other instrument methods because it is a faster, low cost in processing of gathering the research data and it is more convenient. The questions that are prepared by researcher are adopted from past research in similar field. In this research, closedended questions are used. The questionnaire consists three major sections, which includes Section 1(A) (respondent demographic profile), Section 2(B, C, D) (independent variables), and Section 3(E) (dependent variable). In addition, the researchers added another section which is the mediating variables in section $4(F)$. A seven (7) Likert scale is used ranging from "strongly disagree" to "strongly agree".

\section{Data Analysis}

\subsection{Multiple regression: Predictors and independent variable}

The regression model generated in the analysis revealed that $81.9 \%$ of the employee loyalty are by rewards/benefits, training and working condition. All of the three variables are significant. Beta coefficients indicate which variables are important to the model by looking at the largest value (ignoring negative signs). Based on coefficient table, it shows that the highest Beta value in un-standardized coefficient 0.437 (Training) and significant at 0.000 that represent the most influence factors to employee loyalty and followed by rewards and benefit $(B=0.350, p<0.00$ ). Hence, working conditions ( $B$ $=0.276, \mathrm{p}<0.00$ ), is the most critical factors that can influence the employee loyalty among the developer company's employees. 


\subsection{Analyzing the mediating effect}

In order to determine the mediating effect of job satisfaction on the relationship between independent variables and dependent variables, the researcher conducted a multiple regression analysis in 3 steps.

\section{Step 1:}

The first step in conducting the multiple regressions is the regression between independent variables and dependent variables.

\section{Predictors Variable \\ Dependent Variable}

$$
\begin{gathered}
y=-0.272+\beta \times 1+\beta \times 2+0.237 \\
y=-0.272+0.678 \times 1+0.382 \times 2+0.237
\end{gathered}
$$

$\mathrm{y}=$ Employee Loyalty, $\mathrm{X} 1=$ Rewards and Benefits, $\mathrm{X} 2=$ Training

All $\beta$ value for all predictors is significant $(p<0.05)$ with $r$ square $(r 2)$ value of 0.799 . It also discovered that the independent variable which is working condition/working condition is excluded from the regression model because there is Multi-Collinearity issue when variable is have similarity with the independent variables (beta value near to 0.20$)$.

\section{Step 2:}

In the second step, independent variable is regressed against the mediating variable (Job Satisfaction). In other words, the researcher is trying to confirm that the independent variables are significant predictors of the mediator. If the mediator is not associated with the independent variables, then it could not possibly mediate anything.

\section{Independent Variable




$$
\begin{gathered}
y=0.566+\beta \times 1+\beta \times 2+0.215 \\
M e 1=0.566+0.596 \times 1+0.463 \times 2+0.215
\end{gathered}
$$

Me1 = Job Satisfaction, $\mathbf{X} 1=$ Rewards and Benefits, $X 2=$ Training

All $\beta$ values for all predictors are significant $(p<0.05)$ with $r$ square $(r 2)$ value of 0.777

\section{Step 3:}

The third step demonstrates that when the mediator and the independent variable are used simultaneously to predict the dependent variable, the previously significant path between the independent variables and dependent variable (step \#1) is now reduced, if not totally insignificant (Cohen et al, 1983). In other words, if the mediator were to be removed from the relationship, the relationship between the independent and dependent variables would be noticeably reduced. The equation is therefore shown below.

$$
\begin{gathered}
y=-0.407+\beta \times 1+\beta \times 2+0.205 \mathrm{Me} 1+0.238 \\
y=0.407+0.555 \times 1+0.287 \times 2+0.205 \mathrm{Me} 1+0.238 \\
y=\text { Employee Loyalty }
\end{gathered}
$$

Me1 = Job Satisfaction, $\mathbf{X} \mathbf{1}=$ Rewards and Benefits, $\mathbf{X} 2=$ Training

All $\beta$ values for all predictors are significant $(p<0.05)$ with $r$ square $(r 2)$ value of 0.808 It discovered that the mediating variable which is Job Satisfaction, a significant predictor as shown by the significant value of less than 0.05 . Furthermore, the beta values $(\beta)$ of the predictor variables, Rewards and Benefits are lower compared to its beta values $(\beta)$ in step number 1 . The beta value for Rewards and Benefits decreases from 0.678 to 0.555 and the beta value for Training decreases from 0.382 to 0.287 , which confirming the partial mediation of Job Satisfaction on the independent variables Rewards/benefits and training. In addition, the R square $(r 2)$ value in the third equation is higher (0.808) than the R square value (0.799) in the regression analysis in step number 1, which highlighting the mediating effect of Job Satisfaction in the relationship between the two predictors (Rewards/Benefit and training) and the dependent variable which is Employee Loyalty. 


\section{Conclusion and Discussion}

The main objective is to identify which factors that have the strongest and dominant effect and how much those factor do influence to employee loyalty. The finding on the multiple regression tests in chapter four has shown that Beta coefficients indicate which variables are important to the model by looking at the largest value. Based on coefficient table (refers to table 4.9), it shows that the highest value in un-standardized coefficient 0.437 (Training) and significant at 0.000 that represent the most influence factors to employee loyalty and followed by rewards and benefit $(B=.350, p<0.00$ ). Therefore, working conditions ( $B=.276, p<0.00$ ), is the most critical factors that can influence the employee loyalty among the Developer company employees.

The first objective is to investigate the mediating effect, employee job satisfaction on the relationship between training, rewards/benefits and working condition and employee loyalty. In chapter four, the results of finding were answered by the multiple regression tests. In the finding, the researcher conducted a multiple regression analysis in 3 steps in order to determine the mediating effect of employee loyalty on the relationship between the predictors and the dependent variable. The result shows there is all $\beta$ values for all predictors are significant with $r$ square $(r 2)$. It discovered that the mediating variable which is Job Satisfaction is a significant predictor as shown by the significant. Furthermore, the beta values $(\beta)$ of the predictor variables, Rewards and Benefits are lower compared to its beta values $(\beta)$ in step number 1. The beta value for Rewards and Benefits decreases from and the beta value for Training also decreases, which is confirms the partial mediation of Job Satisfaction on the independent variables Rewards/benefits and training. In addition, the R square $(r 2)$ value in the third equation is higher than the $\mathrm{R}$ square value in the regression analysis in step number 1 , which highlights the mediating effect of Job Satisfaction in the relationship between the two predictors (Rewards/Benefit and training) and the dependent variable which is Employee Loyalty.

Based on the empirical results, the researcher proposes that in order to achieve a high level of employee loyalty, an organization must pay great attention and consideration to all factors that provide significant correlations and unique contributions as a good measure in predicting the employee loyalty directly or indirectly. The researchers also conclude that higher level of rewards and benefits, a comfortable and conducive working condition, training programs provided to the employees by organizations and the employee job satisfaction will able to lead a higher level of employee loyalty. Hence, the researcher concludes that the determinants of employee loyalty that company and 
organizations must be valued and the employee job satisfaction; training given to them, rewards and benefits offered to the employee, also the working condition should be a priority of any organization.

\section{References}

[1] Al-Aameri, A.S. (2000), "Job satisfaction and organizational commitment for nurses", Saudi Medical Journal, 21(6), 531-538.

[2] Benn, S., Teo, S. T. T., \& Martin, A. (2015). Employee participation and engagement in working for the environment. http://doi.org/10.1108/PR-10-2013-0179

[3] Burgard, C. (2014). Continuous training, job satisfaction and gender An empirical analysis using German panel data. http://doi.org/10.1108/EBHRM-11-2012-0016

[4] Burton, K. D., Lydon, J. E., D’alessandro, D. U., \& Koestner, R. (2006). The differential effects of intrinsic and identified motivation on well-being and performance: prospective, experimental, and implicit approaches to self-determination theory. Journal of personality and social psychology, 91(4), 750.

[5] Chang C., Chiu C. and Chen A. C. 2010. The effect of TQM practices on employee satisfaction and loyalty in government, Total Quality Management \& Business Excellence, 21(12): 1299-1314.

[6] Chen, C. 2006. Job satisfaction, organizational commitment, and flight attendants turnover intentions: a note, Journal of Air Transport Management, 12, 274-6.

[7] Clark, Diener, Georgellis, \& Lucas. (2008). Lags and leads in life satisfaction: A test of the baseline hypothesis. The Economic Journal, 11 (8), 222-243.

[8] Cohen, P., Cohen, P., West, S., Aiken, L. (1983). Applied Multiple Regression/Correlation Analysis for the Behavioral Sciences. New York: Psychology Press.

[9] Employment Policy Foundation Tabulation and Analysis Bureau of Labor Statistic (2011), Employee Turnover. Retrieved 7 29, 2016, from http://www. sapsustainabilityreport.com/employee-turnover employee turnover is expensive. Retrieved 7 29, 2017, from factsheet: http://www.supersolutions.com/pdfs/ EmployeeTurnoverExpensive 2004.

[10] Fang, Y. (2001), "Turnover propensity and its causes among Singapore nurses: an empirical study", International Journal of Human Resource Management, 12 (5), 859-71.

[11] Jodlbauer, S., Selenko, E., Batinic, B. and Stiglbauer, B. (2012), “The relationship between job dissatisfaction and training transfer", International Journal of Training and Development, 16 (1), 39-53. 
[12] Khuong, M. N., \& Tien, B. D. (2013). Factors influencing employee loyalty directly and indirectly through job satisfaction - A study of banking sector in Ho Chi Minh City, 1(4), 81-95.

[13] Kim, W.G., Leong, J.K. and Lee, Y. (2005). Effect of service orientation on job satisfaction, organizational commitment, and intention of leaving in a casual dining chain restaurant. Hospitality Management, 24, 171-193

[14] Locke, E. (1976), “The nature and causes of job satisfaction”, in Dunnette, M. (Ed.), Handbook of Industrial and Organizational Psychology, Rand McNally, Chicago, IL,. 1297-349.

[15] Phaneuf, W. (2013). Employee loyalty doesn't equal longevity. The Training Source. Retrieved from http://www.leadingforloyalty.com/employee_loyalty.html accessed January 2017.

[16] Sutherland, J. (2013). Employment status and job satisfaction Employment status and job satisfaction.http://doi.org/10.1108/EBHRM-08-2012-0008

[17] Wu, L., \& Norman, I. J. (2006). An investigation of job satisfaction, organizational commitment and role conflict and ambiguity in a sample of Chinese undergraduate nursing students. Nurse education today, 26(4), 304-314. 